ISSN: 1021-7444

\title{
OLEORRESINA DE JÍCAMA Y CALIDAD DE SEMILLA DE FRIJOL INFESTADA CON Acanthoscelides obtectus Say ${ }^{1}$
}

\author{
José Antonio Rangel-Lucio'2, José Mayolo Juárez-Goiz ${ }^{3}$ Edmundo García-Moya ${ }^{4}$ \\ María Dolores Fernández-Andrés ${ }^{2}$, Cesáreo Rodríguez-Hernández ${ }^{4}$,Estéfana Alvarado-Bárcenas ${ }^{2}$
}

\section{RESUMEN}

Oleorresina de jícama y calidad de semilla de frijol infestada con Acanthoscelides obtectus Say. El objetivo de este trabajo fue determinar el efecto de la oleorresina de jícama en la calidad de la semilla de frijol. En laboratorio se obtuvo el extracto de oleorresina mediante HPLC y se detectó la presencia de rotenona $(15 \mathrm{mg} / \mathrm{l})$. Se ensayaron tres concentraciones $\left(\mathrm{C}_{\mathrm{i}}, \mathrm{g} / \mathrm{ml}\right)$ del extracto: $\mathrm{C}_{1}\left(5 \times 10^{-7}, 5 \times 10^{-6}, \ldots .5 \times 10^{-2}\right)$; $\mathrm{C}_{2}\left(1 \times 10^{-2}, 2 \times 10^{-2}, \ldots 6 \times 10^{-2}\right) ; \mathrm{C}_{3}\left(5 \times 10^{-1}, 6 \times 10^{-1}, \ldots 9 \times 10^{-1}\right) \mathrm{y}$ testigo por concentración, en frascos de $300 \mathrm{ml}$ con $50 \mathrm{~g}$ de semilla de frijol (variedades Flor de Mayo, Flor de Junio, Mayocoba) y veinte gorgojos adultos. El ensayo sólo comprendió semillas de frijol tratadas con $\mathrm{C}_{2}$ por 48 horas para evaluar vigor y germinación estándar a los tres y siete días después de la siembra, bajo normas de ISTA. El aumento de $\mathrm{C}_{2}$ fue gradual en el número de plántulas normales y germinación estándar en el primer recuento, en particular con las diluciones $3 \times 10^{-2}$ a 6 × 10-2; en el segundo recuento se confirmó la germinación estándar total con estas mismas diluciones. El frijol Mayocoba en presencia del extracto de semilla de jícama, mantuvo el vigor y valores porcentuales aceptables de germinación estándar de la semilla.

Palabras clave: Germinación estándar, vigor de semilla, gorgojo de frijol, bioinsecticida, bioestimulante.

\begin{abstract}
Yam bean oleoresin and seed quality of common bean infested by Acanthoscelides obtectus Say. The objective oof this investigation was to evaluate the effect of yam bean oleoresin on common bean seed quality and bean weevil control. The oleoresin extract was obtained by the HPLC technique, the presence of rotenone was detected $(15 \mathrm{mg} / \mathrm{l})$. Three concentrations of oleoresin extract were tested $\left(\mathrm{C}^{\mathrm{i}}, \mathrm{g} / \mathrm{ml}\right): \mathrm{C}_{1}\left(5 \times 10^{-7}, 5 \times 10^{-6}, \ldots .5 \times 10^{-2}\right) ; \mathrm{C}_{2}\left(1 \times 10^{-2}, 2 \mathrm{x}\right.$ $\left.10^{-2}, \ldots 6 \times 10^{-2}\right) ; C_{3}\left(5 \times 10^{-1}, 6 \times 10^{-1}, \ldots 9 \times 10^{-1}\right)$ and one control treatment per concentration, applied to recipients of $300 \mathrm{ml}$ with $50 \mathrm{~g}$ of common bean (varieties Flor de Mayo, Flor de Junio, Mayocoba) and 20 adults bean weevils inside. The bioassay only utilized common beans treated with the $\mathrm{C}_{2}$ concentration by $48 \mathrm{~h}$ to evaluate seed vigor and standard germination of common bean at three and seven days after planted, according to ISTA rules. The results demostrated the common bean normal seedlings and standard germination at five days were provocated by gradual $\mathrm{C}_{2}$ increased, particulary $3 \times 10^{-2}$ to $6 \times 10^{-2}$ dilutions at nine days after planted and its confirmed the common bean standard germination.
\end{abstract}

Key words: Standard germination, seed vigor, bean weevil, bioinsecticide, bioestimulant.

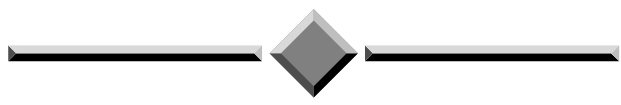

1 Recibido: 11 de enero, 2010. Aceptado: 16 de mayo, 2011.

2 Instituto Tecnológico de Roque. Apdo. Postal 58. CP 38,000. Celaya, Guanajuato, México. arangel_1@yahoo.com

3 Instituto Tecnológico de Celaya. Av. Tecnológico y A. García Cubas S/N. CP 38,110. Celaya, Guanajuato, México.

4 Colegio de Postgraduados. km. 36.5 Carr. México-Veracruz. CP. Montecillo, Texcoco, edo. de México, México. 


\section{INTRODUCCIÓN}

La calidad de la semilla es uno de los factores que afectan el rendimiento potencial de un cultivo y, por lo tanto, el éxito de la actividad agrícola (Sánchez 1972). La capacidad de germinar y el vigor son los dos indicadores de mayor importancia de la calidad de la semilla (Odindo 2007). ISTA (1999) y AOSA (1983) describen el vigor como el mejor indicador de la calidad fisiológica de la semilla, al derivar de la prueba de germinación estándar. Sólo semillas con buenas características físicas y vigorosas lograrían sobrevivir (Delouche y Caldwell 1960) y conferir buen crecimiento vegetal.

En México existen más de veinticinco especies de insectos de importancia económica, que atacan semillas y granos almacenados; quince especies pertenecen a los órdenes Coleoptera y Lepidoptera (Moreno 1992). Los gorgojos en México dañan 40\% de frijol negro almacenado (García-Oviedo 2007), pero Acanthoscelides obtectus (Say) se coloca por arriba de 20\% (Ramírez-Serrano et al. 2003), sin preferencia de variedad de frijol e incluso lenteja (Trabanino 1998), en campo (Schmale et $a l$. 2002) y en confinamiento (Ibarra 2002).

Mientras que la Organización para la Cooperación y el Desarrollo Económico (OCDE) logró bajar 5\% el uso de plaguicidas en el año 2000, en México aumentó $22 \%$ con riesgos severos para la salud humana (Irabien 2008). Ante este problema, los insecticidas orgánicos (bioinsecticidas) han tomado auge en la economía agrícola por el bajo costo, facilidad de preparación, eficacia y menor contaminación. Esto se fundamenta en un período evolutivo de las plantas superior a 400 millones de años, en los que han desarrollado mecanismos de protección tales como la repelencia y acción insecticida (García 1991).

Dado que el control de insectos plaga de cultivos y el mantenimiento de la calidad sanitaria de semillas almacenadas, tradicionalmente utiliza productos químicos sintéticos con respuestas secundarias que alteran el equilibrio ecológico, la salud humana (Waterhouse et al. 1996) y promueve el surgimiento de poblaciones de insectos con mayor resistencia (Bourguet et al. 2000), agresividad (FAO 1999), pérdida de depredadores y polinizadores naturales, resulta imprescindible estudiar y descubrir vías nuevas para su control (Medina 2001). Una alternativa es el uso de extractos de plantas biocontroladores, debido a que presentan metabolitos secundarios (Ducrot 2005), son seguros para el ambiente, la salud humana (Ottaway 2001) y una opción agronómica excelente (Medina 2001). No obstante, estos resultados positivos se han desarrollado con fines insectistáticos (inhibición del desarrollo normal del insecto) más que insecticidas (Celis et al. 2008), en campo y almacén; poco se sabe de las consecuencias que acompañan a la semilla cuando se somete a este tipo de extractos vegetales, en particular sobre la calidad fisiológica, cuyos atributos principales son la germinación y el vigor. Con estos antecedentes se estableció el presente ensayo, con el objetivo de determinar el efecto de la oleorresina de jícama en la calidad de la semilla de frijol.

\section{MATERIALES Y MÉTODOS}

\section{Tratamiento de la semilla de frijol}

Se recuperaron 32,8 $\mathrm{g}$ de oleorresina/100 $\mathrm{g}$ de muestra de semilla de jícama y los espectros registraron la rotenona estándar en un tiempo de retención igual a 9,28 minutos en el extracto vegetal, mientras resina y oleorresina a 9,34 y 9,32 minutos Resina y olerorresina aportaron $10,07 \mathrm{mg} / \mathrm{l}(0,47 \%)$ y $15 \mathrm{mg} / \mathrm{l}$ $(0,68 \%)$ de rotenona, respectivamente. Las diluciones de la oleorresina (DLs, en $\mathrm{mg} / \mathrm{l}$ ) en el bioensayo fueron, Grupo $\mathrm{C}_{1}: 5 \times 10^{-7}, 5 \times 10^{-6}, 5 \times 10^{-5}, 5 \times 10^{-4}, 5 \times$ $10^{-3}, 5 \times 10^{-2}$; Grupo $\mathrm{C}_{2}: 1 \times 10^{-2}, 2 \times 10^{-2}, 3 \times 10^{-2}, 4$ $\times 10^{-2}, 5 \times 10^{-2}, 6 \times 10^{-2}$; Grupo $\mathrm{C}_{3}: 5 \times 10^{-1}, 6 \times 10^{-1}$, $7 \times 10^{-1}, 8 \times 10^{-1}, 9 \times 10^{-1}$; además de testigos (semilla de las variedades de frijol sin tratar). El procedimiento completo del bioensayo aparece en Fernández et al. (2009).

Después de tratar el gorgojo con el extracto de oleorresina en los recipientes de plástico de $300 \mathrm{ml}$, las muestras de $50 \mathrm{~g}$ de semilla de frijol Flor de Mayo, Flor de Junio y Mayocoba se sometieron a limpieza superficial de la cubierta, con la ayuda de una brocha; se usaron guantes quirúrgicos de látex para evitar contaminación de la testa. Las semillas de frijol Flor de Mayo, Flor de Junio y Mayocoba (Azufrado Pimono 78) tienen tamaños pequeño ( $<25 \mathrm{~g} / 100$ semillas), medio ( $>25 \mathrm{~g} / 100$ semillas) y grande ovalado $(>40 \mathrm{~g} / 100$ semillas) (Rosales et al. 2004) y color rosado de la testa con fondo beige, violeta rayado amarillo y amarillo claro (SAGARPA 2002), respectivamente. 


\section{Ensayos de germinación estándar y vigor de semilla}

El ensayo de germinación estándar de la semilla, se practicó mediante la técnica propuesta por ISTA (1999). Esta consistió en colocar sobre papel germinador, 50 semillas de frijol con el micrópilo orientado hacia el extremo superior y en cubrir con otra hoja de características semejantes. Ambas hojas se humedecieron homogéneamente con agua tri-destilada estéril, antes y después de distribuir la semilla y se doblaron para formar un rollo, y los extremos se ligaron para evitar el desplazamiento de la semilla. Esta acción se repitió cuatro veces. Una vez identificados, se introdujeron en posición vertical en bolsas de polietileno y, a su vez, en recipientes plásticos; finalmente se ubicaron en la cámara de germinación a $25^{\circ} \mathrm{C}$, humedad relativa de 90 a $95 \%$ y fotoperíodo de ocho horas. Se hicieron dos evaluaciones de la semilla, a cinco y nueve días después de la siembra (dds). El primer recuento se realizó para determinar germinación estándar de la semilla (G1) con base en las plántulas normales (PN1), así como las anormales (PA) y semillas sin germinar (SG) (v.gr., en estado latente, endurecidas o muertas). El segundo se realizó con la finalidad de evaluar plántulas normales (PN2) desarrolladas de SG durante el período transcurrido, y en estimar germinación estándar en el segundo recuento (G2) con PN2. La germinación estándar total de la semilla de frijol (GT) de cada grupo de concentración $\left(\mathrm{C}_{\mathrm{i}}\right)$, se estimó al sumar los valores de PN1 y PN2 a partir de las 50 semillas utilizadas. Tanto PN, PA y SG, representarían el vigor de la semilla de frijol. Una PN presenta sistema radical, hipocótilo y epicótilo bien desarrollados y sin daño y presencia de cotiledón(es) (ISTA 1999).

El ensayo se estableció en el Laboratorio de Análisis de Semillas del Instituto Tecnológico de Roque, en Celaya, Guanajuato, México, en el año 2007.

\section{Análisis estadístico de los resultados}

En el procedimiento estadístico se transformó a la variable germinación estándar (Gi) a través de la función arc-sen. Los resultados se sometieron a un análisis de varianza para determinar el efecto de los tratamientos y a la prueba de separación de medias (Tukey $\alpha=0,05$ ), mediante el paquete estadístico SAS ver. 9.0 (2002).

\section{RESULTADOS Y DISCUSIÓN}

La efectividad mínima ejercida con $\mathrm{C}_{1}$ y el tiempo rápido de respuesta con $\mathrm{C}_{3}$ del extracto de oleorresina, impidieron la estimación de la concentración letal para controlar el gorgojo de frijol, y dado que las primeras $24 \mathrm{~h}$ del bioensayo fueron prematuras para evaluar la reproducción de gorgojo y 168 h condujo a la muerte de individuos sometidos a estrés derivado del propio confinamiento experimental, y no debido al efecto de los tratamientos, se decidió utilizar solamente la semilla de frijol tratada con $\mathrm{C}_{2}$ y sometida a $48 \mathrm{~h}$ del bioensayo, para realizar las pruebas de germinación estándar y vigor de la semilla. Además, el grupo $\mathrm{C}_{2}$ de concentración del extracto de oleorresina permitió obtener el umbral de mortalidad de $50 \%$ y el ajuste de la concentración letal en el tiempo (48h) y acción deseados en el mismo bioensayo (Fernández et al. 2009).

Los tratamientos, o niveles de dilución del grupo $\mathrm{C}_{2}$, afectaron estadísticamente las variables en las que se concentra la mayor parte de la calidad fisiológica de la semilla de frijol; efecto positivo que también se observó, excepto en SG, entre los genotipos de frijol (Cuadro 1).

Los Coeficientes de Variación (CV) altos para PA, SG, PN2 y G2, fueron debidos a la heterogeneidad de valores registrados, los cuales fueron desde 0 a 20,0 a 17,0 a 13 y 2 a 26 individuos (planta o semilla), respectivamente (Cuadro 1); comportamiento característico de un organismo vivo bajo este tipo de condiciones experimentales. Además, estas variables representan la parte complementaria del proceso de evaluación de la calidad de la semilla, mediante la germinación estándar y el vigor.

La semilla de frijol sufrió una pérdida importante de la calidad fisiológica PN y Gi durante el bioensayo, como lo demuestran los valores arrojados por el testigo inicial (Ti, semilla de frijol sin tratar con el extracto de oleorresina y puesta a germinar antes del establecimiento del bioensayo) y final (Tf, semilla de frijol sin tratar con el extracto, sometida a las mismas condiciones del bioensayo y usada para germinar) (Cuadro 1). La comparación de valores entre testigos (Ti y Tf), prueba la existencia de un deterioro de la semilla que redujo apreciablemente PN (65\%) y, en consecuencia, la germinación estándar (73\%). Egli et al. (2005) afirman que el estrés ambiental redujo 
Cuadro 1. Prueba de separación de medias de variables fisiológicas de la semilla de frijol, tratada en almacenamiento con los niveles de dilución del grupo $\mathrm{C}_{2}\left(1 \times 10^{-2}, 2 \times 10^{-2}, 3 \times 10^{-2}, 4 \times 10^{-2}, 5 \times 10^{-2}, 6 \times 10^{-2}\right)$ del extracto de oleorresina de semilla de jícama. Celaya, Guanajuato, México, 2007.

\begin{tabular}{lccccccc}
\hline Tratamiento & $\begin{array}{c}\text { Plántulas } \\
\text { normales } \\
\text { (primer } \\
\text { recuento) }\end{array}$ & $\begin{array}{c}\text { Germinación } \\
\text { estándar } \\
\text { (primer } \\
\text { recuento) }\end{array}$ & $\begin{array}{c}\text { Plántulas } \\
\text { anormales } \\
\text { (primer } \\
\text { recuento) }\end{array}$ & $\begin{array}{c}\text { Semillas sin } \\
\text { germinar } \\
\text { (primer } \\
\text { recuento) }\end{array}$ & $\begin{array}{c}\text { Plántulas } \\
\text { normales } \\
\text { (segundo } \\
\text { recuento) }\end{array}$ & $\begin{array}{c}\text { Germinación } \\
\text { estándar } \\
\text { (segundo } \\
\text { recuento) }\end{array}$ & $\begin{array}{c}\text { Germinación } \\
\text { estándar } \\
\text { total }\end{array}$ \\
\hline $\begin{array}{l}\text { Tratamiento } \\
\text { inicial }\end{array}$ & $42,25 \mathrm{a}$ & $84,17 \mathrm{a}$ & $3,42 \mathrm{bc}$ & $0,00 \mathrm{~d}$ & $4,33 \mathrm{abc}$ & $8,67 \mathrm{abc}$ & $92,83 \mathrm{a}$ \\
$1 \times 10^{-2}$ & $34,67 \mathrm{c}$ & $69,33 \mathrm{c}$ & $5,17 \mathrm{~b}$ & $4,67 \mathrm{~b}$ & $5,50 \mathrm{ab}$ & $11,0 \mathrm{ab}$ & $80,33 \mathrm{~b}$ \\
$2 \times 10^{-2}$ & $38,00 \mathrm{bc}$ & $76,00 \mathrm{~b}$ & $3,42 \mathrm{bc}$ & $2,58 \mathrm{bc}$ & $6,00 \mathrm{a}$ & $12,0 \mathrm{a}$ & $88,00 \mathrm{a}$ \\
$3 \times 10^{-2}$ & $40,33 \mathrm{ab}$ & $82,00 \mathrm{ab}$ & $4,58 \mathrm{bc}$ & $0,50 \mathrm{~cd}$ & $4,57 \mathrm{abc}$ & $9,2 \mathrm{abc}$ & $91,17 \mathrm{a}$ \\
$4 \times 10^{-2}$ & $42,08 \mathrm{a}$ & $81,92 \mathrm{ab}$ & $3,00 \mathrm{c}$ & $1,33 \mathrm{~cd}$ & $3,67 \mathrm{bc}$ & $7,3 \mathrm{bc}$ & $89,25 \mathrm{a}$ \\
$5 \times 10^{-2}$ & $42,00 \mathrm{a}$ & $82,83 \mathrm{a}$ & $3,00 \mathrm{c}$ & $0,75 \mathrm{~cd}$ & $4,17 \mathrm{abc}$ & $8,3 \mathrm{abc}$ & $91,17 \mathrm{a}$ \\
$6 \times 10^{-2}$ & $41,67 \mathrm{a}$ & $83,33 \mathrm{a}$ & $3,25 \mathrm{bc}$ & $1,58 \mathrm{~cd}$ & $3,17 \mathrm{c}$ & $6,3 \mathrm{c}$ & $89,67 \mathrm{a}$ \\
Tratamiento & & & & & & & $10,5 \mathrm{abc}$ \\
final & $14,58 \mathrm{~d}$ & $22,42 \mathrm{~d}$ & $17,25 \mathrm{a}$ & $12,92 \mathrm{a}$ & $5,25 \mathrm{abc}$ & $32,92 \mathrm{c}$ \\
\hline
\end{tabular}

Valores con la misma literal indican respuesta estadística similar con la prueba de Tukey $\alpha=0,05$.

la germinación y vigor de semillas sanas de soya. La falta de protección ejercida por la capa delgada acuosa formada por la aspersión de las diluciones del extracto de oleorresina, pudo generar desventajas en PN y G1 de las semillas de frijol sin tratar. Ante este tipo de respuestas, ha surgido el término "protección vegetal biológica", efecto que se consigue por ocurrencia natural o por alguna sustancia derivada naturalmente, o de plantas como fuente, y no por medios o agentes sintéticos o químicos (WIPO 2007).

Del mismo modo, Ti y las diluciones 3 x $10^{-2}$ a 6 $\mathrm{x} 10^{-2}$, promovieron la mayor proporción de PN y G1 en el primer recuento (Cuadro 1). Esto significaría que mientras en la semilla de frijol sin tratar se induce una reducción de PN y, por lo tanto, en G1, el extracto de oleorresina de jícama coadyuva a mantener la calidad fisiológica de la semilla de frijol en los primeros cinco días del ensayo; procedimiento que además de controlar el gorgojo de frijol (Fernández et al. 2009), aumentó la tasa de velocidad de germinación de la semilla, objetivo que se logra medir con el primer recuento. Sin embargo, como AOSA (1983) considera apropiada la germinación de la semilla de frijol que registra valores por arriba de $80 \%$, los tratamientos con mayor dilución $\left(3 \times 10^{-2}\right.$ a $\left.6 \times 10^{-6}\right)$ se colocan como tratamientos representativos del estudio. En cambio, la Comisión Veracruzana de Comercialización Agropecuaria (CVCA 2006) sugiere al productor, asegurarse que la semilla de frijol tenga $85 \%$ de germinación al momento de la siembra.

Aunque la semilla de jícama posee diversos compuestos, algunos de ellos tóxicos como la rotenona $\mathrm{y}$ otros rotenoides (Barrera et al. 2004), no se han documentado efectos positivos sobre la calidad fisiológica de la semilla de frijol almacenada, tratada para biocontrolar insectos plaga.

Prueba de la importancia con la que opera el primer recuento de plántulas normales y germinación estándar en estudios de calidad fisiológica de la semilla de frijol, se manifiesta en los valores notablemente superiores que se alcanzan en PN1 y G1, respecto a PN2 y G2 para el mismo tratamiento (Cuadro 1).

La germinación estándar total (GT) confirma el potencial de la semilla en el primer recuento, pues los efectos positivos de las diluciones $3 \times 10^{-2}$ a $6 \times 10^{-6}$, se colocan como tratamientos prometedores para estimular esta variable, al colocarse por arriba del valor estándar propuesto por AOSA (1983) y CVCA (2006), y más allá de $50 \%$ de las consecuencias que sufre la semilla sin tratar, Tf (Cuadro 1). Esta serie de diluciones también 
conjugan las ventajas del aumento gradual sobre GT, pues hicieron crecer la posibilidad de mejorar la calidad fisiológica de la semilla de frijol, ante la exposición del extracto de oleorresina de semilla de jícama. En general, el efecto de las diluciones se ubica por arriba de $60 \%$ del efecto logrado por Tf (Cuadro 1).

Este tipo de resultados, bien podrían ser el antecedente para considerar el extracto de la semilla de jícama como producto promotor de la calidad fisiológica de la semilla de frijol. Se ha probado que los metabolitos secundarios, además del biocontrol de insectos, también pueden mostrar actividad bio-estimulatoria en la misma planta, incluso en otras especies. Por ejemplo, las fitohormonas llamadas brasinoesteroides (Schnabl et al. 2001), aumentan rendimiento y eficiencia del cultivo y vigor de la semilla (Mandava 1988). Además, se han identificado otros compuestos que cumplen con la definición de metabolito secundario y que revelan la actividad regulatoria o estimulatoria del crecimiento de la planta, que incluyen al ácido abscísico, esteroles, cucurbitacinas y juglona naftaquinona (Seigler 1998). Macías et al. (2005) confirmaron que las lactonas sesquiterpenos, comunmente presentes en estrigolactonas, son inductoras específicas de la germinación de Orobanche cumana Wallr. Caso especial de atención, es la respuesta tóxica de aceites esenciales aplicados a semillas almacenadas, con lo cual se evita el ataque de insectos, las protegen durante seis meses $y$, aunque el aspecto pegajoso demerita el atractivo comercial, se mantiene el porcentaje de germinación estándar de la semilla (Shaaya et al. 1997, Tembo y Murfitt 1995). Cualidades que bien se pueden aplicar al extracto de oleorresina, que controla el gorgojo de frijol y mantiene la calidad de la semilla.
Por otro lado, el análisis de varianza practicado a los genotipos de frijol, revela diferencias estadísticas significativas para PN1, PN2, G1, G2, GT y PA. De tal manera, la prueba de separación de medias (Cuadro 2), refleja la similitud de respuestas en la calidad fisiológica de la semilla de frijol en almacén, entre materiales con lazos consanguíneos estrechos (Flor de Mayo y Flor de Junio), excepto en PN y G2, al ser sometidos a bio-control de insectos con extracto de oleorresina de semilla de jícama.

El frijol Mayocoba se mantuvo con el mayor porcentaje de germinación estándar, incluso por arriba del $80 \%$ de germinación ya mencionado, cuando se sometió a las diferentes diluciones del extracto de oleorresina de jícama en almacenamiento (Cuadro 2). Esto significaría que la película protectora del extracto de oleorresina de semilla de jícama, pudo haber evitado el intercambio de humedad y ciertos efectos motivados por la variabilidad de la temperatura, uno de los principales factores asociados con la conservación y capacidad de respuesta a la germinación de los genotipos de frijol (Priestley 1986).

Además del efecto provocado por el extracto de la oleorresina en la germinación estándar total (GT) de la semilla de los genotipos de frijol, otros factores relacionados con su morfología pudieron estar involucrados, tal es el caso de la testa, el color y el tamaño.

Los frijoles Flor de Mayo, Flor de Junio y Mayocoba presentan testa color rosa con fondo beige, violeta rayado amarillo y amarillo claro, respectivamente. El color de la testa de la semilla de frijol está determinado por la presencia y cantidad de flavonoides (Beninger y Hosfield 2003); con lo que se restringe la germinación de la semilla (Debeaujon et al. 2000). Por ejemplo, las

Cuadro 2. Prueba de separación de medias de variables fisiológicas de la semilla de tres genotipos de frijol, tratada en almacenamiento con el extracto de oleorresina de semilla de jícama. Celaya, Guanajuato, México, 2007.

\begin{tabular}{lccccccc}
\hline Frijol & $\begin{array}{c}\text { Plántulas } \\
\text { normales } \\
\text { (primer } \\
\text { recuento) }\end{array}$ & $\begin{array}{c}\text { Germinación } \\
\text { estándar } \\
\text { (primer } \\
\text { recuento) }\end{array}$ & $\begin{array}{c}\text { Plántulas } \\
\text { anormales } \\
\text { (primer } \\
\text { recuento) }\end{array}$ & $\begin{array}{c}\text { Semillas sin } \\
\text { germinar } \\
\text { (primer } \\
\text { recuento) }\end{array}$ & $\begin{array}{c}\text { Plántulas } \\
\text { normales } \\
\text { (segundo } \\
\text { recuento) }\end{array}$ & $\begin{array}{c}\text { Germinación } \\
\text { estándar } \\
\text { (segundo } \\
\text { recuento) }\end{array}$ & $\begin{array}{c}\text { Germinación } \\
\text { estándar } \\
\text { total }\end{array}$ \\
\hline Flor de Mayo & $36,21 \mathrm{~b} *$ & $70,56 \mathrm{~b}$ & $6,37 \mathrm{a}$ & 3,03 & $4,37 \mathrm{~b}$ & $8,75 \mathrm{~b}$ & $79,31 \mathrm{~b}$ \\
Flor de Junio & $35,16 \mathrm{~b}$ & $68,69 \mathrm{~b}$ & $5,59 \mathrm{a}$ & 3,47 & $5,78 \mathrm{a}$ & $11,56 \mathrm{a}$ & $80,25 \mathrm{~b}$ \\
Mayocoba & $39,59 \mathrm{a}$ & $79,00 \mathrm{a}$ & $4,19 \mathrm{~b}$ & 2,62 & $3,59 \mathrm{~b}$ & $7,19 \mathrm{~b}$ & $86,18 \mathrm{a}$ \\
\hline
\end{tabular}

*Valores con la misma literal indican respuesta estadística similar con la prueba de Tukey $\alpha=0,05$. 
semillas de color negro tendrían mayor concentración de estos agentes y mostrar menor tasa de velocidad de germinación, al margen del tamaño. En cambio, estas de color claro muestran imbibición más rápida que las de otro color y germinan primero (Debeaujon et al. 2000, Debeaujon et al. 2003). El color es una característica física que también pudo haber estado ligada a las semillas de frijol Mayocoba, para contar con el mayor porcentaje de germinación estándar en este ensayo. Otra característica morfológica asociada a la respuesta en Mayocoba, es que las semillas de frijol denominados Flores de Mayo, muestran mayor adherencia de la testa a los cotiledones, por lo que la imbibición de agua es lenta (Powell et al. 2005) y la germinación estándar se retrasa.

La variación de color de la testa de la semilla se interpreta como un medio de adaptación de la planta, para germinar en una diversidad de condiciones ambientales (Tenorio-Galindo et al. 2008).

Las semillas pueden exhibir una función distinta en la velocidad de germinación y sensibilidad a la temperatura debido a la variación del tamaño (Nonogaki 2006). La mayor germinación de frijol Mayocoba también pudo estar asociada con el tamaño mayor de la semilla. Esto derivaría en un mayor número de PN, G1 y menor PA, que se reflejó en GT potencial y estadísticamente mayor que los frijoles Flor de Mayo y Flor de Junio (Cuadro 2). Se afirma que la masa de la semilla es un factor biológico importante que afecta la germinación, elongación y crecimiento de las plántulas (Cordazzo 2002, Moegenburg 1996). Hendrix (1984) y Tenorio-Galindo (2008) también establecieron que el tamaño de semillas conduce a mayor porcentaje de germinación o emergencia que las pequeñas. Gholami et al. (2009) indican que una ventaja del tamaño grande deriva en plántulas con mayor tasa de crecimiento que las observadas en semillas pequeñas de frijol. En cambio, Hopper et al. (1979) estiman que si bien las semillas de soya germinan con mayor lentitud que las grandes, tienen la posibilidad de emerger con rapidez en arena y en la mezcla arena-suelo-peat mose.

El extracto de oleorresina de semilla de jícama, utilizado para biocontrolar Acanthoscelides obtectus Say en frijol almacenado, mantuvo los valores porcentuales de la germinación estándar y vigor, variantes de la calidad de la semilla de frijol. De esta manera, el extracto de oleorresina de jícama también se podría utilizar con éxito para bioestimular la calidad de la semilla de frijol, bajo las diluciones $3 \times 10^{-2}$ a 6 × $10^{-2} \mathrm{mg} / 1$.

\section{LITERATURA CITADA}

AOSA (Analist Organization Seed Association). 1983. Seed vigor testing handbook contribution No. 32 to the handbook on seed testing. USA. 88 p.

Barrera, NLL; Bautista BS; Bravo LL; García, SFJL; Alavéz, SD; Reyes, CHR. 2004. Antifungal activity of seed powders, extracts and secondary metabolites of Pachyrhizus erosus (L.) Urban (Fabaceae) against three postharvest fungi. Revista Mexicana de Fitopatología 22(3):356-361

Beninger, CW; Hosfield, GL. 2003. Antioxidant activity of extracts, condensed tannin fractions, and pure flavonoids from Phaseolus vulgaris L. seed coat color genotypes. Journal of Agricultural and Food Chemistry 51(27):7879-7883

Bourguet, D; Genissel, A; Raymond, M. 2000. Insecticide resistance and dominance levels. Journal of Economic Entomology 93:1588-1595.

Celis, A; Mendoza, C; Pachón, M; Cardona, J; Delgado, W; Cuca, LE. 2008. Extractos vegetales utilizados como biocontroladores con énfasis en la familia Piperaceae. Una revisión. Agronomía Colombiana 26(1):97-106.

CVCA (Comisión Veracruzana de Comercialización Agropecuaria). 2006. Monografía de frijol. (en línea). Gobierno del Estado de Veracruz. Veracruz, Veracruz, México. Consulta 15 nov. 2009. Disponible en http:// www. veracruz.gob.mx/portal

Cordazzo, C. V. 2002. Effect of seed mass on germination and growth in three dominant species in southern Brazilian coastal dunes. Braz. J. Bot. 62:427-435.

Debeaujon, I; Leon-Kloosterziel, KM; Koornneef. 2000. Influence of the testa on seed dormancy, germination and longevity in Arabidopsis. Plant Pthysiology 122: 403-414.

Debeaujon, I; Nesi, N; Pérez, P; Devic, M; Grandjean, O; Caboche, M; Lepiniec, L. 2003. Proanthocyanidinaccumulating cells in Arabidopsis testa: regulation of differentiation and role in seed development. Plant Cell 15:2514-2531.

Delouche, JC; Caldwell, WP. 1960. Seed vigor and vigor tests. Proc. Assoc. Off. Seed Anal. 50:124-129.

Ducrot, PH. 2005. Organic chemistry's contribution to the understanding of biopesticida activity of natural products from higher plants. In Regnault, RC; Philogene BJJ; Vincent, C. eds. Biopesticides of plant origin. Lavoiser and Intercept, Ltd. Paris and Andover. p. 47-58.

Egli, DB; Tekrony, DM; Heitholt, JJ; Rupe, J. 2005. Air temperature during seed filling and soybean seed germination and vigor. Crop Sci. 45:1329-1335. 
FAO (Organización de las Naciones Unidas para la Agricultura y la Alimentación). 1999. Cultivating our future. Documento expositivo: El carácter multifuncional de la agricultura y la tierra. (en línea). Conferencia FAO/Países Bajos sobre el Carácter Multifuncional de la Agricultura y la Tierra. Consultado 2 nov. 2009. Disponible en http://www.fao.org/docrep/X2777S/ X2777S00.htm

Fernández-Andrés, MD; Rangel, LJA; Juárez Goiz, JSM; Bujanos-Muñíz, R; Montes, HS; Mendoza EM. 2009. Oleorresina de jícama para controlar Acanthoscelides obtectus Say (Coleóptera:Bruchidae) en semilla de frijol. Agronomía Mesoamericana 20(1):59-69.

García, MM. 1991. Aplicación de polvos y extractos de plantas para el combate del gusano cogollero del maíz (Spodoptera frugiperda) en la región central costera del Estado de Veracruz, México. Departamento de Parasitología Agrícola, Universidad Autónoma Chapingo, estado de México, México. 75 p.

García-Oviedo, JA. 2007. Elabora IPN frijol instantáneo altamente nutritivo. (Nota periodística.) El Universal. Edición: 03/Abril/2007. Consultado 20 marzo 2009. Disponible en http://www.eluniversal.com.mx/articulos/39081.html

Gholami, A; Sharafi, S; Ghasemi, S; Sharafi, A. 2009. Pinto bean seed reserve utilization and seedling growth as affected by seed size, salinity and drought stress. Journal of Food, Agriculture and Environment 7(2):411414.

Hendrix, SD. 1984. Variation in seed weight and its effects on germination in Pastinaca sativa L. (Umbelliferae). Am. J. Bot. 71:795-802.

Hopper, NW; Overholt, JR; Martin, JR. 1979. Effect of cultivar, temperature and seed size on the germination and emergence of soya beans [Glycine $\max (\mathrm{L}$.) Merr.]. Annals of Botany 44(3):301-308.

Ibarra, RJE. 2002. Las bacterias entomopatógenas y el control biológico de insectos. In Loaiza, VJM; Baez, SR. eds. Bacterias Entomopatógenas. Sociedad Mexicana de Control Biológico. Hermosillo, Sonora, México. p. 81 .

Irabien, L. 2008. La OCDE condena uso de pesticidas. Edición: Junio 25, 2008. (en línea). Consultado 11 oct. 2009. Disponible en www.agua.org.mx

ISTA (International Seed Testing Association). 1999. International Rules for Seed Testing Rules 1999. Seed Science and Technology 27 (Supplement):27-31.
Macías, FA; García-Díaz, MD; Carrera, C; de Luque, AP; Rubiales, D; Galindo, CG. 2005. Synthetic studies on germination stimulants of Orobanche species. In $4^{\text {th }}$. World Congress on Allelophy. Charles Sturt University in Wagga Wagga, NSW, Australia. August 21-26. $2752 \mathrm{p}$.

Mandava, NB. 1988. Plant growth.promoting brassinoesteroids. Ann. Rev. Plant Physiol. Plant Mol. Biol. 39: 23-52.

Medina, N. 2001. Uso de extractos botánicos en control de plagas y enfermedades. Avances en el fomento de productos fitosanitarios no sintéticos. Manejo Integrado de Plagas (Costa Rica) 59:76-77.

Moegenburg, S. M. 1996. Sabal palmetto seed size-causes of variation, choices of predators and consequences for seedlings. Oecologia. 106:539-543.

Moreno, ME. 1992. La humedad, su medición e importancia en la conservación de los granos y semillas. In Memorias del Curso Almacenamiento y Conservación de Granos y Semillas. Programa Universitario de Alimentos. Del 23 al 27 de noviembre de 1992. Instituto de Biología. Ciudad Universitaria. UNAM. México. p. 1-34.

Nonogaki, H. 2006. Seed germination. The biochemical and molecular mechanisms. Breeding Science 56:93-105.

Odindo O, A. 2007. Cowpea seed quality in response to production site and water stress (en línea). PhD. Thesis. Ohio State University. Consultado 1 nov. 2009.Disponible en http://dspace.ukzn.ac.za:8080/jspui/handle/10413/292

Ottaway, PB. 2001. The roots of a health diet? Chemistry and Industry 22:42-44.

Powell AA, Corbineau F, Franca-Neto J, Lechappe J, Mesterhazy A, Pritchard HW, Tarp G. 2005. Towards the future in seed production, evaluation and improvement. Seed Science and Technology 33:265-281.

Priestley, DA. 1986. Seed aging. Cornell University Press. Ithaca, New York. 304 p.

Ramírez-Serrano, A; Vera-Graziano, J; Aguilera-Peña, M; Garza-García, R. 2003. Preferencia, supervivencia y fecundidad de Acanthoscelides obtectus (Say) en cuatro genotipos de frijol resistentes a Apion godmani (Wagner). Agrociencia 37:195-202.

Rosales, SR; Acosta, GJA; Muruaga, MJS; Hernández, C JM; Esquivel, EG; Pérez, HP. 2004. Variedades mejoradas de frijol del Instituto Nacional de Investigaciones Forestales, Agrícolas y Pecuarias. Libro Técnico Núm. 6. Centro de Investigación Regional del Centro Campo Experimental Valle de México. p. 148. 
SAGARPA (Secretaría de Agricultura, Ganadería, Desarro1lo Rural, Pesca y Alimentación). 2002. Guía Técnica para la Descripción Varietal de Frijol (Phaseolus vulgaris L.) (en línea). Sistema Nacional de Inspección y Certificación de Semillas (SNICS). México, D.F. México. Consultado 27 oct. 2009 Disponible en http:// www.sagarpa.gob.mx/snics/Comunidad\%20snics/ GUIAS\%20A/Frijol/FRIJOL.DOC.

SAS (Statistical Analysis System). 2002. The SAS System for Windows 9.0. SAS Institute, Inc. North Caroline. USA.

Sánchez, MR. 1972. Evaluación de la calidad de semilla de frijol (Phaseolus vulgaris L.) en Costa Rica. Tesis Mag. Sc. Turrialba, Costa Rica. Instituto Interamericano de Costa Rica. 61 p.

Schmale, I; Wäckers, FL; Cardona, C; Dorn, D. 2002. Field Infestation of Phaseolus vulgaris by Acanthoscelides obtectus (Coleoptera: Bruchidae), parasitoid abundance and consequences for storage pest control. Environmental Entomology 31(5):859-863

Schnabl, H; Roth, U; Friebe, A. 2001. Brassinoesteroidinduced stress tolerance of plants. Phytochemistry 5: 169-183.

Seigler, DS. 1998. Plant secondary metabolism. Kluwer Academic Publishers, Norwell, MA, USA. p. 367-398.
Shaaya, E; Kostjukovsky, M; Eilberg, J; Sukprakarn, C. 1997. Plant oils as fumigants and contact insecticides for control of stored-product insects. Journal of Stored Products Research 33:7-15.

Tembo, E; Murfitt, RFA. 1995. Effect of combining vegetable oil with primiphos-methyl of stored wheat against Sitophilus granaries (L.). Journal of Stored Products Research 31(1):77-81.

Tenorio-Galindo, G; Rodríguez-Trejo, DA; López-Ríos, G. 2008. Efecto del tamaño y color de la semilla en la germinación de Cecropia obtusifolia Bertol (Cecropiaceae). Agrociencia 42(5):585-593.

Trabanino, R. 1998. Guía para el manejo integrado de plagas invertebrados en Honduras. Escuela Agrícola Panamericana. El Zamorano, Honduras. Zamorano Academic Press. 156 p.

Waterhouse, D; Carman WJ, Schottenfeld D, Gridley G and Maclean S. 1996. Cancer incidence in the rural community of Tecumseh, Michigan. Cancer 77:763-770.

WIPO (World Intellectual Property Organization). 2007. Seed suspensions from 'Lupinus albus', isolated compounds thereof and use as biological plant strengthening agent. (WO/2007/090438). (en línea). Geneva, Switzerland. Consultado 27 nov. 2009. Disponible en http://www. wipo.int/pctdb/en/wo.jsp?wo=2007090438 